\title{
Efficacy of posterior decompression and fixation based on ossification-kyphosis angle criteria for multilevel ossification of the posterior longitudinal ligament in the thoracic spine
}

\author{
Hiroshi Uei, MD, Yasuaki Tokuhashi, MD, Masashi Oshima, MD, Masafumi Maseda, MD, \\ Masahiro Nakahashi, MD, and Enshi Nakayama, MD
}

Department of Orthopaedic Surgery, Nihon University School of Medicine, Tokyo, Japan

\begin{abstract}
OBJECTIVE The range of decompression in posterior decompression and fixation for ossification of the posterior longitudinal ligament in the thoracic spine (T-OPLL) can be established using an index of spinal cord decompression based on the ossification-kyphosis angle (OKA) measured in the sagittal view on MRI. However, an appropriate OKA cannot be achieved in some cases, and posterior fixation is applied in cases with insufficient decompression. Moreover, it is unclear whether spinal cord decompression of the ventral side is essential for the treatment of OPLL. In this retrospective analysis, the efficacy of posterior decompression and fixation performed for T-OPLL was investigated after the range of posterior decompression had been set using the OKA.

METHODS The MRI-based OKA is the angle from the superior margin at the cranial vertebral body of the decompression site and from the lower posterior margin at the caudal vertebral body of the decompression site to the prominence of the maximum OPLL. Posterior decompression and fixation were performed in 20 patients. The decompression range was set so that the OKA was $\leq 23^{\circ}$ or the minimum if this value could not be achieved. Cases in which an OKA $\leq 23^{\circ}$ could and could not be achieved were designated as groups $U$ ( 13 patients) and $O$ ( 7 patients), respectively. The mean patient ages were 50.5 and 62.1 years $(p=0.03)$ and the mean preoperative Japanese Orthopaedic Association (JOA) scores were 5.9 and $6.0(p=0.9)$ in groups $U$ and $O$, respectively. The postoperative JOA score, rate of improvement of the JOA score, number of levels fused, number of decompression levels, presence of an echo-free space during surgery, operative time, intraoperative blood loss, and perioperative complications were examined.
\end{abstract}

RESULTS In groups $U$ and $O$, the mean rates of improvement in the JOA score were $50.0 \%$ and $45.6 \%(p=0.3)$, the numbers of levels fused were 6.7 and $6.4(p=0.8)$, the numbers of decompression levels were 5.9 and $7.4(p=0.3)$, an echo-free space was noted during surgery in $92.3 \%$ and $42.9 \%$ of cases $(p=0.03)$, the operative times were 292 and 238 minutes $(p=0.3)$, and the intraoperative blood losses were 422 and $649 \mathrm{ml}(p=0.7)$, and transient aggravation of paralysis occurred as a perioperative complication in 2 and 1 patient, respectively.

CONCLUSIONS There was no significant difference with regard to the recovery rate of the JOA score between patients with (group U) and without (group O) sufficient spinal cord decompression. The first-line surgical procedure of posterior decompression and fixation with the range of posterior decompression set as an OKA $\leq 23^{\circ}$ before surgery involves less risk of postoperative aggravation of paralysis and may result in a better outcome.

https://thejns.org/doi/abs/10.3171/2017.12.SPINE17549

KEYWORDS ossification-kyphosis angle; ossification of the posterior longitudinal ligament in the thoracic spine; posterior decompression; posterior fixation

$\mathrm{T}$ He ossification-kyphosis angle (OKA) in the sagittal view on MRI can be used as an index of the decompression range in posterior decompression and fixation for ossification of the posterior longitudinal ligament in the thoracic spine (T-OPLL; Fig. 1). Our previous findings showed that the critical point of success or failure in mechanical decompression of the thoracic spinal cord was an OKA of $23^{\circ}$ on intraoperative diagnosis by ultrasonography. ${ }^{15}$ In that previous study, patients with echofree space showed a better recovery rate than patients with

ABBREVIATIONS JOA = Japanese Orthopaedic Association; LOA = local ossification angle; OKA = ossification-kyphosis angle; OLF = ossification of the ligamentum flavum; T-OPLL = ossification of the posterior longitudinal ligament in the thoracic spine.

SUBMITTED May 15, 2017. ACCEPTED December 5, 2017.

INCLUDE WHEN CITING Published online May 4, 2018; DOI: 10.3171/2017.12.SPINE17549. 

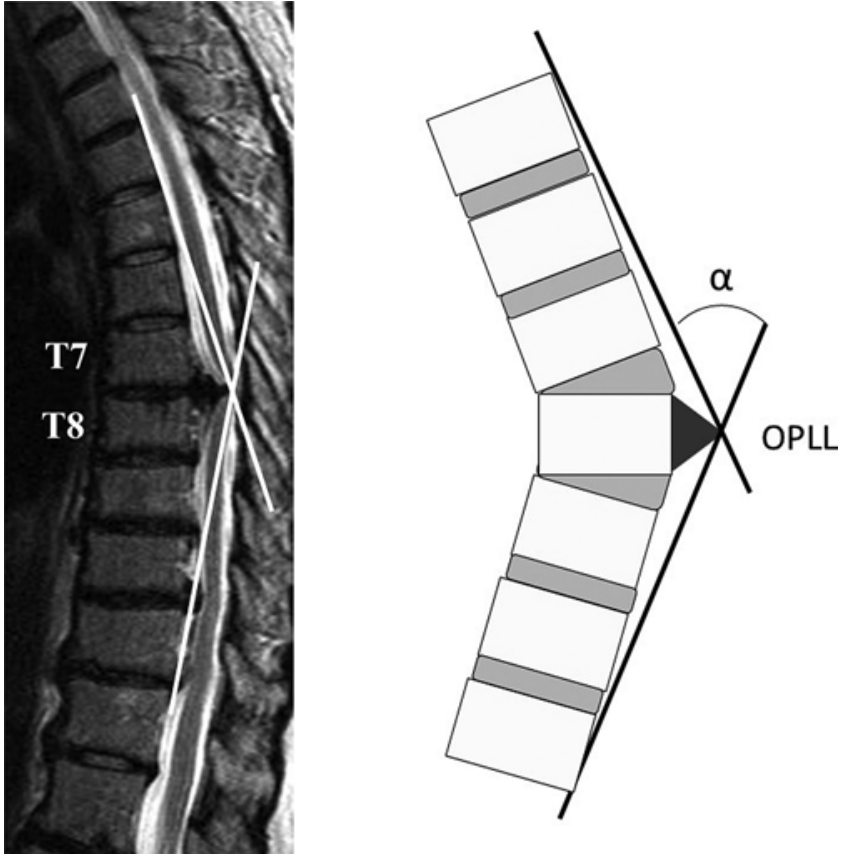

FIG. 1. The ossification-kyphosis angle (OKA) is the kyphosis angle formed by the cranial-side posterior superior margin of the vertebral body, posterior maximally protruding apex of the ossified lesion, and caudal-side posterior inferior margin of the decompression range in the sagittal view on MRI.

no echo-free space. In the present retrospective study, we investigated the efficacy of posterior decompression and fixation in patients with multilevel T-OPLL in whom the OKA had been measured in the sagittal view on MRI and the range of decompression had been determined before surgery.

\section{Methods}

\section{Patient Population}

The subjects were 20 patients who had undergone surgery for T-OPLL since 2002, when we started to set the decompression range with the OKA at $\leq 23^{\circ}$ if possible and at the minimum if $\leq 23^{\circ}$ was not possible. All patients had undergone posterior decompression and fixation. Cases in which an OKA $\leq 23^{\circ}$ could and could not be achieved were designated as groups U (13 patients: 6 males and 7 females) and $\mathrm{O}$ (7 patients: 3 males and 4 females; $p=0.6$ for sex), respectively, and outcomes were analyzed prospectively (Table 1 ). The mean patient ages were 50.5 and 62.1 years $(p=0.03)$ and the mean preoperative Japanese Orthopaedic Association (JOA) scores ${ }^{18}$ were 5.9 and $6.0(p=0.9)$ in groups $U$ and $O$, respectively.

In the patients in group $\mathrm{U}$, maximum spinal cord compression by OPLL occurred at the upper thoracic level (T1-4) in 4 patients, middle thoracic level (T5-8) in 6, and lower thoracic level (T9-12) in 3; in group U, it occurred at the upper and middle thoracic levels in 2 and 5 patients, respectively $(p=0.1)$. The type of OPLL was beaked in 6 patients, continuous waveform in 1 , and continuous cylindrical in 6 in group U; it was beaked in 1 patient, continuous waveform in 2 , continuous cylindrical in 3 , and linear
TABLE 1. Baseline characteristics in patients with (group U) and without (group 0) sufficient spinal cord decompression

\begin{tabular}{|c|c|c|c|}
\hline Characteristic & $\begin{array}{c}\text { Group } \\
\text { U }\end{array}$ & $\begin{array}{c}\text { Group } \\
0\end{array}$ & $\begin{array}{c}p \\
\text { Value }\end{array}$ \\
\hline No. of patients & 13 & 7 & \\
\hline Age at surgery in yrs & $50.5(9.4)$ & $62.1(12.1)$ & 0.03 \\
\hline \multicolumn{4}{|l|}{ Sex, no. (\%) } \\
\hline Male & $6(46.1)$ & $3(42.9)$ & 0.6 \\
\hline Female & $7(53.8)$ & $4(57.1)$ & \\
\hline Preoperative JOA score & $5.9(1.9)$ & $6.0(2.8)$ & 0.9 \\
\hline \multicolumn{4}{|l|}{$\begin{array}{l}\text { Level of max cord compression, } \\
\text { no. (\%) }\end{array}$} \\
\hline Upper (T1-4) & $4(30.8)$ & $2(28.6)$ & 0.1 \\
\hline Middle (T5-8) & $6(46.2)$ & $5(71.4)$ & \\
\hline Lower (T9-12) & $3(23.1)$ & $0(0)$ & \\
\hline OPLL no. & $5.7(3.4)$ & $5.4(4.0)$ & 0.8 \\
\hline \multicolumn{4}{|l|}{ OPLL type, no. (\%) } \\
\hline Beaked & $6(46.2)$ & $1(14.3)$ & 0.3 \\
\hline Continuous waveform & $1(7.7)$ & $2(28.6)$ & \\
\hline Continuous cylindrical & $6(46.2)$ & $3(42.9)$ & \\
\hline Linear & $0(0)$ & $1(14.3)$ & \\
\hline Canal occupancy ratio & $42(11.2)$ & $52.9(14.7)$ & 0.1 \\
\hline Coexistence of OLF, no. (\%) & $11(84.6)$ & $5(71.4)$ & 0.4 \\
\hline $\begin{array}{l}\text { Ossification kyphosis angle in de- } \\
\text { grees }\end{array}$ & $17.2(3.6)$ & $28.1(1.5)$ & $<0.001$ \\
\hline
\end{tabular}

Data are shown as the mean (standard deviation) unless otherwise indicated.

in 1 in group $\mathrm{O}(\mathrm{p}=0.3)$. The canal occupancy ratio at the cord level with maximum compression was $42 \%$ in group $\mathrm{U}$ and $52.9 \%$ in group $\mathrm{O}(\mathrm{p}=0.1)$. Ossification of the ligamentum flavum (OLF) was concomitantly present in 11 and 5 patients $(\mathrm{p}=0.4)$ and the OKA was $17.2^{\circ}$ and $28.1^{\circ}$ in groups $\mathrm{U}$ and $\mathrm{O}$, respectively $(\mathrm{p}<0.001)$.

\section{Surgical Procedures}

The MRI-based OKA is the angle from the superior margin at the cranial vertebral body of the decompression site and from the lower posterior margin at the caudal vertebral body of the decompression site to the prominence of the maximum OPLL (Fig. 1). ${ }^{15}$ Measurements of OKA were performed by two independent observers. Assessment of intra-examiner and inter-examiner reliability showed excellent agreement (intraclass correlation coefficient [ICC] 0.90 and 0.87 , respectively). The decompression range was set such that OKA was $\leq 23^{\circ}$ or the minimum if this value could not be achieved. In surgery, in cases with a decompression range localized in the thoracic over the lumbar spine, pedicle screws were inserted into at least 3 vertebral bodies on the cranial and caudal sides within a range exceeding the decompression range by 1 vertebral body. In cases requiring a decompression range extending to the cervical spine, fixation with a lat- 
eral mass screw was applied to at least 3 vertebral bodies on the cranial side.

Surgery was performed with the patient prone and the head fixed with a Mayfield clamp, except in cases with lower thoracic compression. The surgical field was exposed, then pedicle screws were inserted and fixed on one side with temporary rods, followed by posterior decompression in the planned range. The bilateral rods were tightened after decompression. In situ fixation was applied without correction for dekyphosis, and the bilateral rods were connected using a transverse connector. Echography was performed during surgery to evaluate decompression. The effectiveness of posterior decompression of the spinal cord was evaluated based on the presence of echo-free space (gap between the ventral side of the spinal cord and the OPLL).${ }^{15}$ The condition of decompression of the spinal cord was judged both on the longitudinal axis image and on the horizontal axis image, with echo-free space indicating sufficient decompression. If decompression was not observed on ultrasonography, no additional decompression was performed and the wound was closed to complete surgery.

\section{Outcome Evaluation}

The postoperative JOA score, rate of improvement of the JOA score, number of levels fused, number of decompression levels, preoperative and postoperative thoracic kyphosis (T5-12), preoperative and postoperative thoracic kyphosis of the decompression site, presence of an echofree space during surgery, operative time, intraoperative blood loss, and perioperative complications were examined. Hirabayashi's improvement rate was used as the rate of improvement of the JOA score. ${ }^{3}$ Statistical analysis was performed using IBM SPSS software version 18 (SPSS Inc.). We performed a t-test, Mann-Whitney U-test, Wilcoxon signed-rank test, and chi-square test with the significance level at $5 \%$.

\section{Results}

In groups $\mathrm{U}$ and $\mathrm{O}$, the numbers of levels fused were 6.7 and $6.4(\mathrm{p}=0.8)$, the numbers of decompression levels were 5.9 and $7.4(\mathrm{p}=0.3)$, the operative times were 292.2 and 238.4 minutes $(\mathrm{p}=0.3)$, and the intraoperative blood losses were 422.1 and $649.1 \mathrm{ml}(\mathrm{p}=0.7)$, respectively (Table 2 ). An echo-free space was noted during surgery in $92.3 \%$ and $42.9 \%$ of cases $(p=0.03)$ and the mean durations of postoperative follow-up were 86.3 and 34.5 months $(\mathrm{p}=0.03)$ in the respective groups. Postoperative JOA scores were 8.5 and $7.6(p=0.4)$ and the rates of improvement of JOA scores were $50.0 \%$ and $45.6 \%$ $(\mathrm{p}=0.3)$ in groups $\mathrm{U}$ and $\mathrm{O}$, respectively. Any condition prior to surgery was not aggravated after surgery in any patient. Regarding perioperative complications, transient aggravation of paralysis occurred in 2 cases in group $\mathrm{U}$ and 1 case in group $\mathrm{O}$, dural tear occurred in 2 cases in group $\mathrm{U}$, massive bleeding occurred in 1 case in group $\mathrm{O}$, epidural hemorrhage occurred in 1 case in group $\mathrm{U}$, and surgical site infection occurred in 1 case in group U. We compared the radiographic parameters preoperatively and postoperatively. In groups $\mathrm{U}$ and $\mathrm{O}$, preoperative thoracic
TABLE 2. Comparison of clinical parameters in patients with (group U) and without (group 0) sufficient spinal cord decompression

\begin{tabular}{lccc}
\hline \multicolumn{1}{c}{ Parameter } & $\begin{array}{c}\text { Group } \\
\text { U }\end{array}$ & $\begin{array}{c}\text { Group } \\
\mathrm{O}\end{array}$ & $\begin{array}{c}\mathrm{p} \\
\text { Value }\end{array}$ \\
\hline No. of patients & 13 & 7 & \\
\hline No. of levels fused & $6.7(2.7)$ & $6.4(3.0)$ & 0.8 \\
\hline No. of decompression levels & $5.9(3.1)$ & $7.4(4.0)$ & 0.3 \\
\hline Operation time in mins & $292.2(103.9)$ & $238.4(60.7)$ & 0.3 \\
\hline Blood loss in ml & $422.1(230.8)$ & $649.1(614.8)$ & 0.7 \\
\hline Existence of echo-free space, & $12(92.3)$ & $3(42.9)$ & 0.03 \\
no. (\%) & & & \\
\hline Follow-up in mos & $86.3(57.2)$ & $34.5(20.1)$ & 0.03 \\
\hline Postoperative JOA score & $8.5(1.1)$ & $7.6(3.3)$ & 0.4 \\
\hline Recovery rate & $50.0(20.1)$ & $45.6(38.3)$ & 0.3 \\
\hline Periop complications, no. $(\%)$ & & & \\
\hline Transient paralysis & $2(15.4)$ & $1(14.3)$ & \\
\hline Dural tear & $2(15.4)$ & $0(0)$ & \\
\hline Massive bleeding (>1500 ml) & $0(0)$ & $1(14.3)$ & \\
\hline Epidural hemorrhage & $1(7.7)$ & $0(0)$ & \\
\hline Surgical site infection & $1(7.7)$ & $0(0)$ & \\
\hline
\end{tabular}

Data are shown as the mean (standard deviation) unless otherwise indicated.

kyphosis was $21.0^{\circ}$ and $28.1^{\circ}(\mathrm{p}=0.06)$, postoperative thoracic kyphosis was $22.6^{\circ}$ and $30.7^{\circ}(\mathrm{p}=0.2)$, preoperative thoracic kyphosis of the decompression site was $17.3^{\circ}$ and $26.4^{\circ}(\mathrm{p}=0.1)$, and postoperative thoracic kyphosis of the decompression site was $20.6^{\circ}$ and $26.0^{\circ}(\mathrm{p}=0.06)$, respectively. We also compared the preoperative and postoperative radiographic parameters in each group. In group $\mathrm{U}$, there was no significant change in thoracic kyphosis $(\mathrm{p}=0.8)$ or thoracic kyphosis of the decompression site $(\mathrm{p}=0.1)$ between the preoperative and postoperative parameters. In group $\mathrm{O}$, there was no significant change in thoracic kyphosis $(p=0.3)$ or thoracic kyphosis of the decompression site $(\mathrm{p}=0.8)$ between the preoperative and postoperative parameters. A beaked-type OPLL at the middle thoracic level in a 47-year-old woman is shown in Fig. 2. The minimum OKA was $28^{\circ}$. Posterior fixation (T4-12) and posterior decompression (T5-11) were performed (Figs. 3 and 4A and B). Intraoperative ultrasonography showed the remaining spinal cord compression on the ventral side after posterior fixation (Fig. 4C). The JOA score increased from 9 before surgery to 11 after surgery (recovery rate: $100 \%$ ).

\section{Discussion}

The concept of the K-line has been proposed in selecting surgical procedures for OPLL in the cervical spine with kyphosis: ${ }^{2}$ this concept suggests that the outcome obtained by laminoplasty alone is poor and that anterior fixation should be selected as the first choice, although posterior decompression and fixation should be chosen 

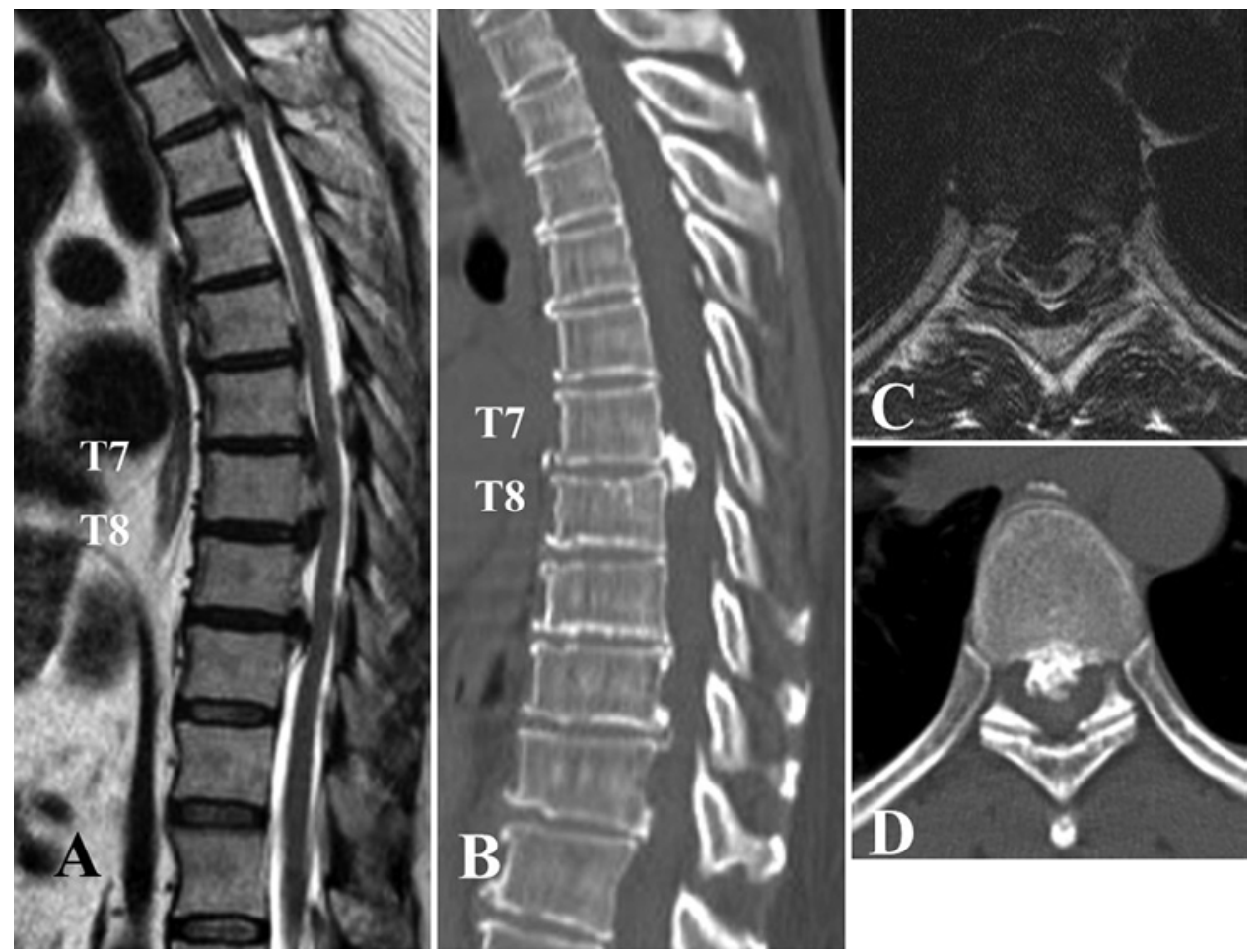

FIG. 2. Middle thoracic level OPLL in a 47-year-old woman. This case involved a beaked-type OPLL and the minimum OKA was $28^{\circ}$. Posterior fixation (T4-12) and posterior decompression (T5-11) were performed. The preoperative JOA score of 9 increased to 11 after surgery (recovery rate: 100\%). A: Preoperative sagittal T2-weighted MR image. B: Preoperative sagittal CT. C: Preoperative axial T2-weighted MR image at the T7-8 level. D: Preoperative axial CT at the T7-8 level.

for high-risk cases. This is a clear method of selecting the surgical procedure. However, it has been difficult to establish an index to determine an appropriate decompression range and surgical procedure for thoracic OPLL, and various surgical procedures to achieve spinal cord decompression have been proposed. Anterior decompression via an anterior approach is rational with regard to spinal cord decompression, but the approach to the upper thoracic level is limited given the presence of the thorax, and spinal cord decompression is limited for cases requiring extensive decompression and those in which the spinal cord is sandwiched between the OPLL and the posterior wall of the spine or the OLF. ${ }^{1}$ Anterior decompression through a posterior approach may be adopted in such cases, ${ }^{4,14}$ but it has a high risk of paralysis in cases of a beaked-type OPLL at the apical vertebra of the thoracic kyphosis.

In our study, there was no complete paralysis in either group. Transient paralysis occurred in 2 cases in group $\mathrm{U}$ and 1 case in group $\mathrm{O}$. Among these transient cases was 1 case of beaked-type OPLL in group $\mathrm{U}$, and the patient showed an improvement rate of $60 \%$ at the final follow-up. These results showed that posterior decompression and fixation surgery has a lower incidence of perioperative paralysis and stable surgical outcomes regardless of the type of OPLL. In upper thoracic level OPLL, anterior decompression and fixation through the posterior approach can lead to anteroposterior decompression over a wide range, but postoperative aggravation of paralysis can occur and the incidence of complications is high. Takahata et al. found a mean improvement rate of $52 \%$, but postoperative aggravation of paralysis occurred in 8 (26.7\%) of 30 patients and did not recover to a grade better than that before surgery in 5 of these cases..$^{14} \mathrm{Hu}$ et al. reported a mean improvement rate of $60.4 \%$ but with postoperative aggravation of paralysis in $9(34.6 \%)$ of 26 patients, including complete paralysis in 2 cases. ${ }^{4}$ Combined anteroposterior circumferential decompression is a rational method with regard to spinal cord decompression, but it is highly invasive for patients in terms of operative time and blood loss because surgery is divided into two stages. ${ }^{8}$

The decompression effect of posterior decompression and fusion surgery for T-OPLL is likely to be insufficient because of physiological thoracic kyphosis, but it is advantageous in that progression of thoracic kyphosis after laminectomy can be prevented, indirect decompression can be applied with mild correction, ${ }^{12}$ and spinal cord compression-induced paralysis can be prevented. ${ }^{17} \mathrm{In}$ addition, there is little direct manipulation of the spinal cord, such as excision of an ossified lesion, and this results in a low incidence of postoperative aggravation of paralysis, making the surgery less invasive and safer than other procedures. ${ }^{10,11}$

Indexes for determining the optimum range for posterior decompression and fixation are unsatisfactory. Ito et al. reported radiographic measurement of the local ossification angle (LOA). ${ }^{6}$ This was the angle at the intersection between a line from the superior posterior margin at the cranial vertebral body of the maximum OPLL to the top of the OPLL with a beaked type, and a line from the lower posterior margin at the caudal vertebral body of the 


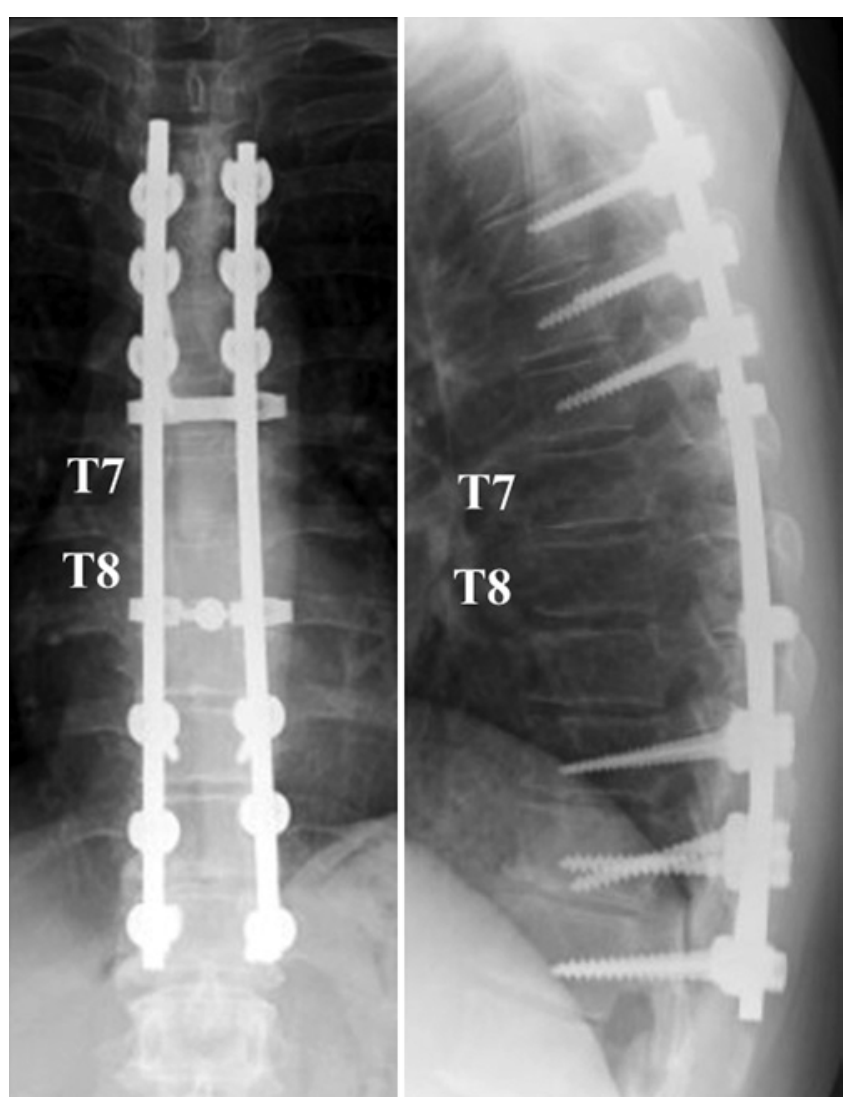

FIG. 3. Images obtained in a 47-year-old woman. Left: Postoperative radiography, posteroanterior view. Right: Postoperative radiography, lateral view.

maximum OPLL to the top of the OPLL with a beaked type. The authors recommended anterior decompression for cases with an LOA $<28^{\circ}$ or posterior decompression with fixation when an LOA was $\geq 28^{\circ}$. Their study was a retrospective multiinstitutional analysis and included various surgical procedures; therefore, it is difficult to determine the optimum range for posterior decompression and fixation according to the LOA. We chose to use the OKA because this angle reflects physiological kyphosis, the thickness of the ossified lesion of the PLL, and spinal cord compression. ${ }^{15}$ One advantage is that the range of posterior decompression with an $\mathrm{OKA} \leq 23^{\circ}$ can be measured before surgery and the application of indirect decompression can mostly be ensured. We previously reported outcome data for various types of surgeries for T-OPLL. ${ }^{15} \mathrm{In}$ 13 patients with echo-free space, who underwent posterior decompression with or without posterior fusion, the recovery rate of the JOA score was $62.7 \%$. On the other hand, in 2 patients who underwent anterior decompression and fusion, the recovery rate was $33.3 \%$. In 4 patients who underwent posterior decompression with no echo-free space and OPLL resection via the posterolateral approach combined with posterior fusion, the recovery rate was $39.4 \%$. We also reported that there is a critical point of posterior "indirect" decompression at $23^{\circ}$ of the OKA of the decompression site. Therefore, a first-line surgical procedure of posterior decompression and fixation with the range of posterior decompression set at an $\mathrm{OKA} \leq 23^{\circ}$ before sur- gery has less risk of postoperative aggravation of paralysis and is likely to result in stable outcomes.

One problem with this method is that there is a limit to the level to which posterior decompression can be extended, depending on the size of the ossified lesion, and posterior decompression of the spinal cord may not be achieved, even with extensive laminectomy. Selecting a surgical procedure for such cases is difficult. Kato et al. described modified anterior decompression and fixation through a posterior approach, in which resection of the vertebral arch and its pedicle enabled safer and extensive decompression. ${ }^{7}$ Imagama et al. secured a sufficient surgical field by resection of the vertebral arch and its pedicle and part of the ribs and performed anterior decompression from a posterior approach. ${ }^{5}$ These reports had only a small number of cases, and an accumulation of cases is required for verification, but these procedures may improve the safety of direct decompression via a posterior approach to the spinal cord.

We previously reported that in 13 patients with echofree space, who underwent posterior decompression with or without posterior fusion, the recovery rate of the JOA score was $62.7 \% .{ }^{15}$ In the current study, the rate of improvement of the JOA score in group U was an average of $50.0 \%$, which seemed to be inferior to our results in the previous study. The difference between our two studies in the rate of improvement of the JOA score showed the possibility of a heterogeneous surgical population. In the previous study, the average preoperative JOA score of 4.3 points improved to an average of 8.6 points at the final follow-up. In the current study, the average preoperative JOA score of 5.9 points in group $\mathrm{U}$ improved to an average of 8.5 points at the final follow-up. The JOA score at the final follow-up in group $\mathrm{U}$ was as good as the score in the previous study; however, the preoperative JOA score in group $\mathrm{U}$ was superior to that in the previous study. $\mathrm{Pa}$ tients in the previous study had more severe conditions than those in the current study. Hence, cases with sufficient spinal cord decompression could be guaranteed to improve to an average of 8.5 points at the final follow-up. On the other hand, the postoperative JOA score in group O was an average of 7.6 points. There was no significant difference with regard to the recovery rate of the JOA score between patients with and without sufficient spinal cord decompression. However, cases with sufficient spinal cord decompression may achieve a better outcome.

A high incidence of perioperative paralysis makes surgery for T-OPLL difficult. ${ }^{16}$ A posture change from supine to a prone position during surgery decreases spinal cord evoked potentials, which may also be decreased by resection of the spinous process alone in some cases. ${ }^{13}$ Aggravation of paralysis just by sitting after surgery has also been reported. ${ }^{9}$ Therefore, surgery for T-OPLL should be carefully performed to prevent perioperative complications. Sufficient indirect decompression of the spinal cord by posterior decompression and fixation with the OKA $\leq 23^{\circ}$ is ideal, but comparable outcomes can be achieved with a higher OKA.

Posterior decompression and fixation have low invasiveness in terms of operative time and blood loss, and the incidence of perioperative complications is low compared with those of other surgical procedures. ${ }^{4-11}$ Therefore, 


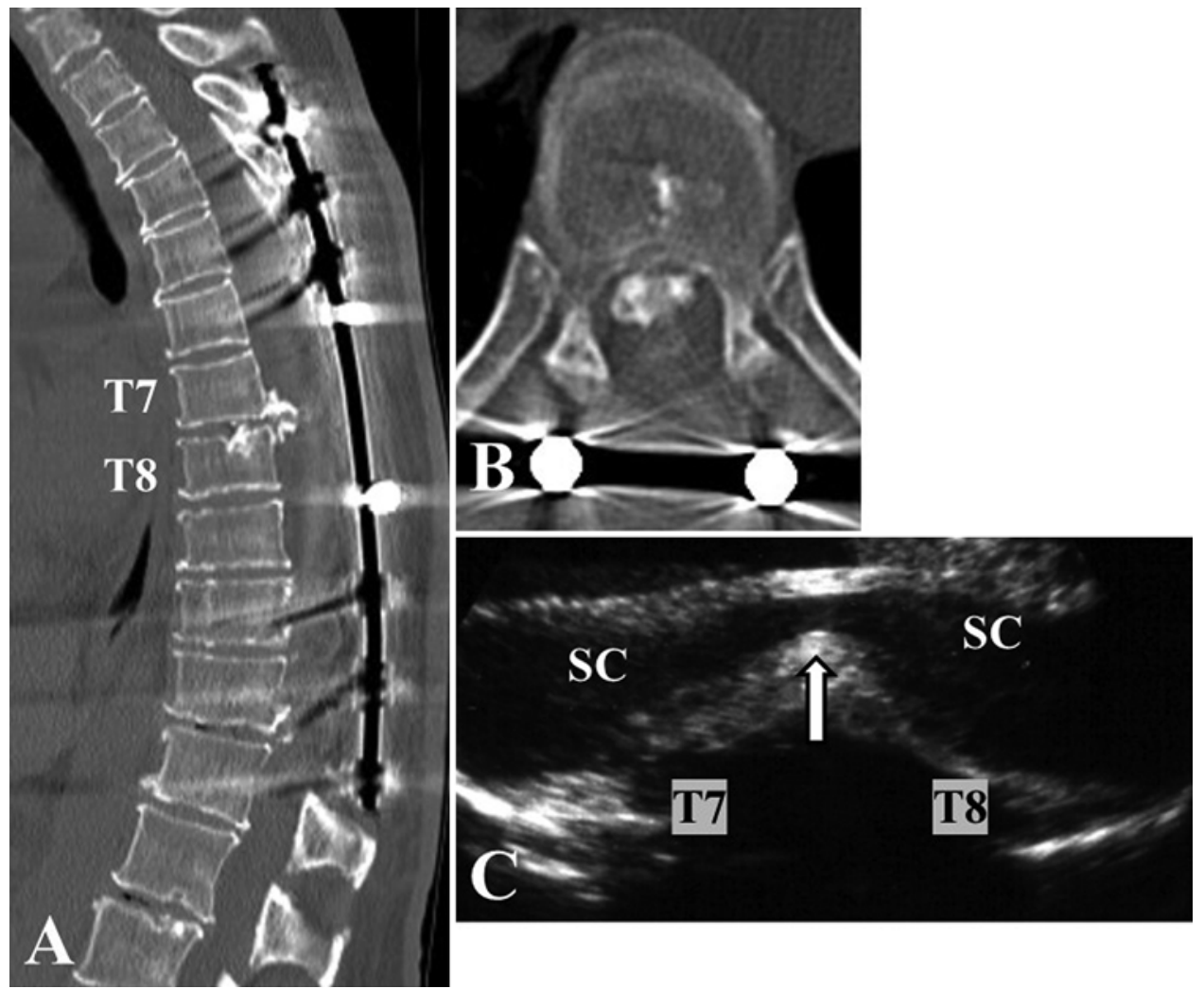

FIG. 4. Images obtained in a 47-year-old woman. A: Postoperative sagittal CT. B: Postoperative axial CT obtained at the T7-8 level. C: Intraoperative diagnosis was made using ultrasonography. Arrow indicates the beaked-type OPLL at the T7-8 level. Decompression of the spinal cord (SC) was not achieved on the ventral side.

even if sufficient spinal cord decompression cannot be achieved, a satisfactory outcome is possible if perioperative paralysis can be avoided. This conclusion is reached in the context of several limitations of the study, including the influence of unknown surgical variables and the lack of verification of the acceptable range of OKA, which could not be performed because of the small number of cases at a single institution.

\section{Conclusions}

Surgery for T-OPLL should be carefully performed to prevent perioperative complications. Posterior decompression and fixation have low invasiveness in terms of operative time and blood loss, and the incidence of perioperative complications is low compared with those of other surgical procedures. There was no significant difference with regard to the recovery rate of the JOA score between patients with (group U) and without (group O) sufficient spinal cord decompression. The first-line surgical procedure of posterior decompression and fixation with the range of posterior decompression set at an OKA $\leq 23^{\circ}$ before surgery involves less risk of postoperative aggravation of paralysis and may achieve a better outcome.

\section{References}

1. Fujimura Y, Nishi Y, Nakamura M, Toyama Y, Suzuki N: Long-term follow-up study of anterior decompression and fusion for thoracic myelopathy resulting from ossification of the posterior longitudinal ligament. Spine (Phila Pa 1976) 22:305-311, 1997

2. Fujiyoshi T, Yamazaki M, Kawabe J, Endo T, Furuya T, Koda $\mathrm{M}$, et al: A new concept for making decisions regarding the surgical approach for cervical ossification of the posterior longitudinal ligament: the K-line. Spine (Phila Pa 1976) 33:E990-E993, 2008

3. Hirabayashi K, Miyakawa J, Satomi K, Maruyama T, Wakano K: Operative results and postoperative progression of ossification among patients with ossification of cervical posterior longitudinal ligament. Spine (Phila Pa 1976) 6:354-364, 1981

4. Hu P, Yu M, Liu X, Liu Z, Jiang L: A circumferential decompression-based surgical strategy for multilevel ossification of thoracic posterior longitudinal ligament. Spine J 15:24842492,2015

5. Imagama S, Ando K, Ito Z, Kobayashi K, Hida T, Ito K, et al: Resection of beak-type thoracic ossification of the posterior longitudinal ligament from a posterior approach under intraoperative neurophysiological monitoring for paralysis after posterior decompression and fusion surgery. Global Spine J 6:812-821, 2016

6. Ito K, Yukawa Y, Horie Y, Kato F: Surgical treatment for ossification of posterior longitudinal ligament in thoracic spine: influence of local ossification angle. J Jpn Spine Res Soc 18:608-609, 2007

7. Kato S, Murakami H, Demura S, Yoshioka K, Hayashi H, Yokogawa N, et al: Gradual spinal cord decompression through migration of floated plaques after anterior decompression via a posterolateral approach for OPLL in the thoracic spine. J Neurosurg Spine 23:479-483, 2015 
8. Kawahara N, Tomita K, Murakami H, Hato T, Demura S, Sekino Y, et al: Circumspinal decompression with dekyphosis stabilization for thoracic myelopathy due to ossification of the posterior longitudinal ligament. Spine (Phila Pa 1976) 33:39-46, 2008

9. Koda M, Mannoji C, Inada T, Kamiya K, Ota M, Maki S, et al: Neurological deterioration induced by sitting in patients after cervicothoracic posterior decompression with instrumented fusion surgery for ossification of the longitudinal ligament: two cases reports. BMC Res Notes 8:133, 2015

10. Matsumoto M, Chiba K, Toyama Y, Takeshita K, Seichi A, Nakamura K, et al: Surgical results and related factors for ossification of posterior longitudinal ligament of the thoracic spine: a multi-institutional retrospective study. Spine (Phila Pa 1976) 33:1034-1041, 2008

11. Matsumoto M, Toyama Y, Chikuda H, Takeshita K, Kato T, Shindo $\mathrm{S}$, et al: Outcomes of fusion surgery for ossification of the posterior longitudinal ligament of the thoracic spine: a multicenter retrospective survey: clinical article. J Neurosurg Spine 15:380-385, 2011

12. Matsuyama Y, Sakai Y, Katayama Y, Imagama S, Ito Z, Wakao N, et al: Indirect posterior decompression with corrective fusion for ossification of the posterior longitudinal ligament of the thoracic spine: is it possible to predict the surgical results? Eur Spine J 18:943-948, 2009

13. Nakanishi K, Tanaka N, Kamei N, Hiramatsu T, Ujigo S, Sumiyoshi N, et al: Resection of spinous processes can cause spinal cord injury in patient with ossification of the posterior longitudinal ligament in the thoracic spine. Spinal Cord $\mathbf{5 2}$ (Suppl 3):S19-S21, 2014

14. Takahata M, Ito M, Abumi K, Kotani Y, Sudo H, Minami A: Clinical results and complications of circumferential spinal cord decompression through a single posterior approach for thoracic myelopathy caused by ossification of posterior longitudinal ligament. Spine (Phila Pa 1976) 33:1199-1208, 2008

15. Tokuhashi Y, Matsuzaki H, Oda H, Uei H: Effectiveness of posterior decompression for patients with ossification of the posterior longitudinal ligament in the thoracic spine: usefulness of the ossification-kyphosis angle on MRI. Spine (Phila Pa 1976) 31:E26-E30, 2006
16. Xu N, Yu M, Liu X, Sun C, Chen Z, Liu Z: A systematic review of complications in thoracic spine surgery for ossification of the posterior longitudinal ligament. Eur Spine J 26:1803-1809, 2017

17. Yamazaki M, Mochizuki M, Ikeda Y, Sodeyama T, Okawa A, Koda M, et al: Clinical results of surgery for thoracic myelopathy caused by ossification of the posterior longitudinal ligament: operative indication of posterior decompression with instrumented fusion. Spine (Phila Pa 1976) 31:14521460,2006

18. Yonenobu K, Abumi K, Nagata K, Taketomi E, Ueyama K: Interobserver and intraobserver reliability of the Japanese Orthopaedic Association scoring system for evaluation of cervical compression myelopathy. Spine (Phila Pa 1976) 26:1890-1894, 2001

\section{Disclosures}

The authors report no conflict of interest concerning the materials or methods used in this study or the findings specified in this paper.

\section{Author Contributions}

Conception and design: Uei, Tokuhashi. Acquisition of data: Uei. Analysis and interpretation of data: Uei, Oshima, Maseda, Nakahashi, Nakayama. Drafting the article: Uei. Critically revising the article: Uei. Reviewed submitted version of manuscript: Uei, Tokuhashi. Approved the final version of the manuscript on behalf of all authors: Uei. Statistical analysis: Uei. Administrative/ technical/material support: all authors. Study supervision: Uei, Tokuhashi.

\section{Correspondence}

Hiroshi Uei: Nihon University School of Medicine, Tokyo, Japan. uei.hiroshi@nihon-u.ac.jp. 